\title{
REVIEW
}

\section{A NEW COMPREHENSIVE MONOGRAPH ON KHITAN}

CHINGGELTEI [Qingge'ertai] 清格尔泰, WU Yingzhe 吴英喆 and JIRUHE 吉如何: Qidan xiaozi zai yanjiu 契丹小字再研究 [Further research on Khitan Small Script]. Vols. I-III, Beijing, 2017, 2336+20 pp.

This three-volume book is the latest comprehensive monograph on the Khitan monuments written in the Khitan Small (or Assembled) Script. The last three similar works written in the 21st century with a similar aim are the works of Chinggeltei (2002), Wu Yingzhe (2012) and Liu Pujiang and Kang Peng (2014).

The work under review (henceforth CWJ) is in all respects a richer and more comprehensive work than the former ones. It is the publication of the latest results of the work of a research group founded and led for a long time by the famous professor Chinggeltei ( $† 27$ December 2013). His work was continued by his pupils and two of them are the co-editors of this work.

The three volumes of the book are titled as follows:

Vol. 1: Further Research on Khitan Small Script and Photocopies of the Monuments

[English translations by the reviewers] (Qidan xiaozi zai yanjiu ji ziliao tuban 契丹小字再研究及资料图版),

Vol. 2: A Collection of Khitan Small Script Corpus (Qidan xiaozi ziliao zongbian 契丹小字资料总编),

Vol. 3: Indexes (Suoyin 索引).

Volume 1

The preface (zixu 自序) gives a concise summary of the past century of research on Khitan language, obviously focusing on the Khitan Small Script (henceforth abbreviated as KSS). 
The first part of Chapter 1 of Vol. 1 (第一编第一章第一节) is an overview of the history of the discovery of the Khitan scripts containing some general remarks with scattered references to scholarly literature. References are sorely missing, e.g. when the authors write about 'some scholars' who, by means of DNA analysis, identified Daurs as the descendants of Khitans, p. 3.

An enumeration of the known Khitan Large Script (KLS) monuments Nos. 115 is included on pp. 5-9 (Chapter 1), followed by the KLS monuments of less importance (coins, smaller scripts, etc.), the latter not being discussed in the book. The list of the KSS monuments Nos. 1-44 on pp. 9-16 is supplemented by a short record of five recently found yet unpublished monuments (pp. 16-17). These are the following:

1073 Da 大, Epitaph for Gu Taishi: Da Liao guo Gu Taishi muzhiming 大遼國故太 師墓誌銘;

1091 ShiZh 侍, Epitaph for Gu Shizhong (1015-1090): Gu Shizhong muzhiming 故 侍中墓誌銘 (also Shizhong 侍中, cf. Apatóczky and Kempf 2017: 117);

1099 Wo 斡, Epitaph for Prince Wotelan (1073-1099): Yelü Wotelan langjun muzhiming 耶律斡特懶朗君墓誌銘 (also Wotelan 斡特懶, cf. Apatóczky and Kempf 2017: 118);

1101 Shi 師, Epitaph for Yelü Taishi (1038-1101): Yelü Taishi muzhiming 耶律太師 墓誌銘 (also: Taishi 太師, cf. Apatóczky and Kempf 2017: 119);

1109 Tian 天, Epitaph for Yelü Tianni: Yelü Tianni Taishi muzhiming 耶律天你太師 墓誌銘.

Pages 18-23 feature a chart of the full, as well as the abbreviated Chinese titles of both KLS and KSS monuments. Part 2 of Chapter 1 (第二节) gives a detailed outline of the scrutiny of KSS, carried out by the Khitan Script Research Group (Qidan wenzi yanjiu xiaozu 契丹文字研究小组, co-founded by the Mongolian Language and Literature Research Unit at the Inner Mongolia University and the Research Institute of Nationalities at the Chinese Academy of Sciences) from 1985 on. The authors describe the stages of decipherment from the matching of KSS glyphs to Chinese personal names, toponyms, kinship terms (etc.) through their utilisation in the reading of further lexicon, as well as in sketching up the grammatical setup of Khitan. A supplementary bibliography of Chinese and (very limited) foreign literature follows on pp. $50-83$.

Chapter 2 (第二章) is dedicated to the description of the visible characteristics of KSS, one of the three main features glyphs have, along with their phonetic and semantic values (the latter two are discussed in Chapters 3 and 4, respectively). A separate part describes both KLS and KSS systems, the latter is completed by a comprehensive chart of glyph forms on pp. 92-104 and an appendix of KLS character chart on pp. 107-126.

The phonetic values of the KSS glyphs are introduced in Chapter 3 (pp. 127353). This chapter is one of the most important ones of the book as it sums up the phonetic reconstruction of the already deciphered KSS glyphs in Part 2 (pp. 149338) with an overview chart added on pp. 341-353. This part provides a wide-range review of the glyphs, introducing the stages of decipherment from the point of view 
of the history of their research. Glyphs are paired either with their reconstructed phonetic manifestations ( $n$ i yin 拟音) or with their hypothetical readings (jiadingxing niyin 假定性拟音); e.g. No. 69 坴 has a reconstructed reading: ri; No. 68 北 has hypothetical readings: biff or us (p. 178). Glyphs are marked by cardinal numbers. Nos. 9 and 10 are exceptions, since their readings are under No. 1. A reference to such dispositions would have been adequate. Features like vowel harmony, vowel reading rules, traces of Chinese $-p,-t,-k$ codas of the entering tone as represented in KSS are thoroughly discussed in Part 1 (pp. 128-148).

Chapter 4 (第四章) on pp. 354-600 (and not starting on p. 355 as it is written in the English Table of Contents) deals with the semantics of KSS monuments. The authors analyse the semantic features of KSS materials as combinations of single glyphs. They distinguish three types of morphemes: (1) units having their own meaning; (2) units that have no meaning when isolated, while they have meaning in compounds; these may have either lexical or grammatical functions; (3) sequences with both lexical and grammatical functions. The authors separate two types of semantic groups of the glyphs based on their functionality, i.e. ones carrying 'primary meaning' (zhuziyi 主字义) and ones having only secondary (or 'attached', cf. the English translation of the Table of Contents 'Additive Elements' fuziyi 附字义) meaning' (or rather 'function'), a new terminus technicus introduced by the authors for glyphs representing suffixes or particles. The former category is described in Part 1, pp. 355-488, the latter on pp. 489-594, supplemented by charts of glyphs of the second category already deciphered on pp. 595-600. Examples for the above partition: glyph representing a lexeme: 天 DAY (p. 403); glyph representing a grammatical function: the plural marker 矢 $l i$ (pp. 538-539). 天 DAY was earlier treated as a logograph, a glyph only the meaning of which is known. In this case, we learn from the Liaoshi 遼史 that the word was pronounced as /närä/. The claim that -li is a plural marker is interesting, but needs further corroboration.

Photocopies of (the rubbings of) the extant KSS monuments constitute an unnumbered Chapter on pp. 601-864 (and not starting on p. 603 as it is written in the English Table of Contents). The inclusion of good quality photocopies in most cases is of great help to scholars having no access to the monuments; however, as some inscriptions are simply too large to fit the page in a reasonably legible size, the help is not always effective (e.g. p. 659 or p. 834).

\section{Volume 2}

The second volume contains the corpus of the known KSS monuments presented in four groups according to the time of their first publication (1: 1922-1977, pp. 8661022; 2: 1977-2002, pp. 1023-1223; 3: 2002-2010, pp. 1224-1448; 4: after 2010, pp. 1449-1592) saving a fifth chapter for the minor texts of metal (bronze mirrors, coins) and stone tablet inscriptions (pp. 1593-1615). The discussion of the material is structured around the following pattern:

1. A short introduction of the monument expounding the historical background, place and date of unearthing, wherever these are identifiable, as well as physical and textual description. 
2. A transcript of the monument using Khitan fonts with interlinear glossing in modern Mandarin (simplified characters) wherever possible.

3. A transcript of the adjacent Chinese text (in the rare cases if any).

\section{Volume 3}

The last volume consists of two main indexes: the Index of KSS vocabulary (pp. 1617-2314) and the Index of KSS glyphs (pp. 2315-2333). The KSS vocabulary index contains more than 10,400 entries listing not only lexemes, but also suffixed forms, syntagmas, morphemes and suffixes. The authors consider one unit what is written within one 'box' (on the 'boxes' see below). From the earlier list, the authors have removed 9 pieces for being 'non-existent', and added 73 new items. The Index of KSS glyphs gives the number of occurrences limited to 10 in every case. The three numerals next to the abbreviated title of the source represent the number of the line and that of the glyph group within the line, while the encircled third stands for the actual glyph if it constitutes a part of a group (the third is only marked if needed) e.g.: 15 疗: 宣 $20-9$ (1), points to the glyph No. 015 疗 being the 1 st glyph of the 9th glyph group ('box') in the 20th line of the Xuan inscription.

A Postscript by Wu Yingzhe completes the book (pp. 2334-2336).

A great change compared to earlier mainland Chinese works is the practice that the old Chinese parts of the Khitan-Chinese bilingual texts are not rendered in simplified Chinese characters in the transcripts, giving thus no ground for misinterpretations. The glossing of the Khitan texts is in simplified script as pointed out above, but that does not restrict its usability. The transcript of Khitan texts in Menksoft Khitan fonts provides great readability.

The Table of Contents along with the Preface and the Postscript translated into English at the end of Vol. 3 will be useful for scholars not reading Chinese; however, for such a generously edited opus magnum, a basic proofreading of these few pages would have been welcome.

The volumes are printed in the traditional Chinese way, i.e. the book reads from right-to-left. A somewhat confusing method of pagination is applied throughout the volumes. Solely Chinese numerals are used, but parts not belonging to the main text, such as the Preface, Tables of Contents, Postscript, restart pagination from 1, whereas the pagination of the main text runs through the volumes. The whole trend is then broken at the end of Vol. 3 where the pages containing the English translations are numbered the opposite way around in a Western, left-to-right manner, starting from the very last page as 1 until p. 19, which is then preceded (followed?) by p. 2336. Thus Vol. 3 has two sets of pp. 1-9, and there is no p. 1616 marked either at the end of Vol. 2 or at the beginning of Vol. 3.

The work has two great merits: it made accessible more material in KSS than any earlier publication and it is an outstanding help for those who work with the Khitan material.

In the last comprehensive overview (Apatóczky and Kempf 2017: 115-122), 41 major inscriptions were only mentioned. In this book, however, the 44 major and 17 minor inscriptions are also published. In this case, 'publication' means that we 
find photocopies, transcriptions in KSS fonts, and the transcriptions are in many cases glossed by Chinese translations. The whole corpus was Romanised, the Romanisation of the inscriptions has been digitalised. The corpus includes more than 100,000 items. In the Index, the units are listed according to their current number in the List in growing order. The Index contains 10,407 different units. A unit may be a basic word or a derivation, or a suffixed form or a morpheme with only grammatical function. As it is known, the KSS is written in 'boxes', or are 'assembled', hence the other name of the KSS: Assembled Script, a term first used by G. Kara (1987). A unit may consist of maximum 8 glyphs in the following order:
$\mathrm{ab}$
$\mathrm{cd}$
e f
$\mathrm{gh}$

For technical reasons, in the case of Romanisation a linear transposition has hitherto been used with dots denoting that the glyphs of the item pertain to the same 'box', e.g. the example above would be: <a.b.c.d.e.f.g.h>. Now in CWJ a hyphen is inserted $<\mathrm{a}-\mathrm{b}-\mathrm{c}-\mathrm{d}-\mathrm{e}-\mathrm{f}-\mathrm{g}-\mathrm{h}>$. The items also have a current number. Let us take an example from page 1619:

\begin{tabular}{|l|l|l|l|l|l|}
\hline 1445 & 㚐行公 & $57-220-341$ & xo-mú-er & 6 & $\begin{array}{l}\text { 仁15-1, 仁18-15, 湳28- } \\
7, \text { 清25-25, 敌39-14, } \\
\text { 回28-18 }\end{array}$ \\
\hline $\begin{array}{l}\text { current } \\
\text { number } \\
\text { der } \\
\text { original or- }\end{array}$ & $\begin{array}{l}\text { numerals of } \\
\text { the List }\end{array}$ & $\begin{array}{l}\text { Romani- } \\
\text { sation }\end{array}$ & $\begin{array}{l}\text { occur- } \\
\text { rences }\end{array}$ & $\begin{array}{l}\text { sources line and posi- } \\
\text { tion in the line, e.g. } \\
\text { Ren15-1 is the inscrip- } \\
\text { tion Renxian (1072) line } \\
15, \text { the first box }\end{array}$ \\
\hline
\end{tabular}

From the Index, it is easy to collect phrases, e.g. for <xo.mu.er $>$ 'coffin':

$<$ dor.GREAT xo.mu.er $>$ (Ren14-19/15-1)

$<$ GREAT xo.mu.er $>$ (Ren18-15, Nan28-7, Qing25-25),

$<$ dor xo.mu.er $>$ (DiX39-12/14),

$<$ dor xo.mu.er $>$ (Hui28-17/18).

The GREAT 又 (373) xomur was a type of coffin, < dor $>$ ५ (218) is a logograph for SEAL, used in the meaning 'ceremonial', that is 'the ceremonial coffin of the tomb'.

In the Index, all occurrences are given, and thus the frequency of a unit in the corpus can be easily identified. In the Index, one can find many hapaxes, units that occur only once; and, on the other hand, units that occur several hundred times. Frequency will be an important aid in deciphering the language; however, one has to distinguish Khitan words and syllables used in transcriptions for Chinese. 
The deciphering of the script is also advancing. The last overview of the stage of deciphering the KSS can be found in the publication by Wu and Janhunen (2010: 38-48, see also Shimunek 2017: 419-445). In fact, at present we have to work with the so-called Romanisation of the glyphs or graphs. The glyphs are drawings and are used for rendering, in most cases, syllables. Romanisation is reflecting the view of earlier scholars on the possible reading of the glyphs. The reading, as it is known, was first attached to glyphs which occurred in transcriptions of Chinese proper names and words. Their value depends on the reconstructed pronunciation of the original Chinese. As we see, Romanisation is neither a phonetic, nor a phonological reproduction of the Khitan words. For the time being, we have to accept the opinion of Wu and Janhunen (2010: 39) who stated that 'they [i.e. the Romanised transcription of the glyphs] are best understood as intermediate labels for the Khitan characters concerned'.

In comparison to $\mathrm{Wu}$ and Janhunen's work, there are some small changes concerning the consonantal Latin stock used. The Romanisation $<\mathrm{ts}>$ has been changed to $<\mathrm{ch}>$ : 质 (031) (only on p. 40 of WJ $<\mathrm{tz}>$, but not in their Index), which has been changed by $\mathrm{CWJ}$ to $<\mathrm{chi}>$. The Romanisation $<\mathrm{dz}>$ in the case of $\%$ (354) has been

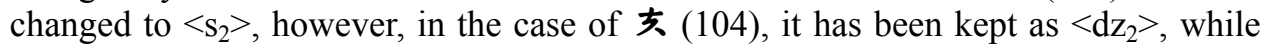
there is no $<\mathrm{dz}>$ in the system. These smaller inconsistencies do not hamper the work.

One would expect that with the inclusion of the new inscriptions many new glyphs appear. On the contrary, WJ had in their List of Glyphs 459 items, while the last glyph in the List of CWJ is numbered 378. True, there are some new items inserted. CWJ introduced a new custom. Until this publication, if a new glyph was found, it was put at the end of the List and got a new number, which was a safe, even if a little cumbersome, procedure. According to the new system, when a newly found glyph appeared, it got an extended number attached to an already existing one. In most cases it denotes an alloglyph as in: 坐 (261.1) which may be an alloglyph of 坐 $(260)<\mathrm{l}>$. While (261) is one of the most frequent glyphs, (261.1) occurs, at least as initial, only once in Yong30-11, where the facsimile is not quite clear. Another example is 与 (361.1), which is an alloglyph of in Hui2-2. In such cases, it seems to be reasonable to give an extended numeral to a new, uncertain item. This is, however, not always the case.

It was among others $\mathrm{Wu}$ who supposed that the so-called dotted variants, or at least many of them, signalised grammatical gender; so far the dotted variant has marked the male and the undotted one the female gender (of course, the absence of a dot may be due to many other reasons, e.g. simple negligence). From the cases of the numerals and the colours we know that in Khitan these gender variants may have different suffixes (see Róna-Tas 2016: 131), but in the known cases the dotted and undotted variants pertain together. It is unlikely that $\quad(082)<\ddot{u} e>$ and its undotted form 艺 (082.1) would not pertain together. For the latter form, CWJ gives the Romanisation $<$ aju $>$ (adza/adzu). On pp. 186-187, there is a detailed indication for the reading. Though the reasoning of CWJ is not very convincing, of course, we cannot exclude that their suggestion may be valid. If they are right, the extended numeration (082.1) raises more problems than it solves. 
In the monograph of WJ (2010: 38), there are 38 items listed as allographs or alloglyphs of other characters. All of them are included in CWJ, too, but in numerous cases an alloglyph has no reading in CWJ as: 소 (350, occurring four times), which is an alloglyph of the very frequent 爸 $(254)<\mathrm{d}>$, but $(350)$ has no reading, though with the highest probability it has to have the same reading: $<\mathrm{d}>$.

Some items are not even alloglyphs, but in fact identical, like 久 (171) and 久 (215). In this case (215) is correctly deleted and no other glyph appears in its place, so number 215 of the List is void.

With such a great corpus in hand, new readings offer themselves. These new readings have to receive great attention. For instance, 33 (146) was read by Kane (2009: 52) as <giú>, because he found that <giú.ün> transcribes Chinese jun 君. WJ (2010: 263) transcribed it as $<$ gi $>$, and wrote that it may have the same function as is (336) and both may be negation particles used before verbs (p. 157). In CWJ, the glyph 33 (146) has a new reading: <es>, surely supposing a relationship with Mongolian ese, while is (366) got a new reading <ul $>$ in connection with Mongolian $\ddot{u} l \ddot{u}$. The problem here is that both occur before the verb $<$ ci.er $>$ 'written' in identical phrases:

pures es cier 止劦全乃执公 (295.097.244 146 162.341) <p.úr.s es ci.er>: 'the descendants (of his eldest brother, Mr Ong Liu) were not written (in the records)' (Xiang9-12/14).

ay pures ul cier キ业夜全的机公 (122 295.097.244 336 162.341) <ai p.úr.s ul ci.er> 'the (other) descendants of the father were not written (in the records)' (DiX26$17 / 20)$.

It is, of course, possible that $e s$ and $u l$ were interchangeable in the language of the Khitan inscriptions. The glyph <es $>33$ (146) occurs 17 times in Xiang and never in DiX, while $<\mathrm{ul}>$ is (336) can be found 15 times in DiX and never in Xiang. Xiang was written in 1091 and DiX in 1114. Nonetheless both are found in Dao (1101), $<$ es $>10$ times, $<$ ul $>$ also 10 times. The earliest occurrence of $<\mathrm{es}>$ is in the inscription Guang (1053) where it occurs 16 times. The glyph $<\mathrm{ul}>$ (336) is first occurring in $\mathrm{Yu}$ (1072), also 16 times. In the whole corpus, the glyph $<$ es $>33$ (146) occurs 465 times, while $<\mathrm{ul}>$ is (366) only 130 times. Thus, before hasty conclusions are drawn, further research is needed to clear their respective functions. This case may show that the monograph under review does not only bring new solutions, but it also raises new problems and gives food for further investigations.

As a summary, we may conclude that the work of Chinggeltei, Wu Yingzhe, Jiruhe and their colleagues is a great achievement. It contains almost all of the hitherto known Khitan texts written in the Khitan Small or Assembled Script. The presentation of the material is at the highest level of modern scholarship, and the work will be fundamental for any further research.

\section{Abbreviations}

CWJ = CHINGGELTEI, WU Yingzhe and JIRUHE 2017 (the work under review)

KLS = Khitan Large Script

KSS $=$ Khitan Small Script

WJ = WU Yingzhe and J. JANHUNEN (2010) 


\section{References}

ApatóczKy, Ákos Bertalan and Béla KempF 2017. 'Recent Developments on the Decipherment of the Khitan Small Script.' AOH 70/2: 109-133.

CHINGGELTEI 2002. Qidan xiaozi shidu wenti 契丹小字释读问题 [Problems in the decipherment of the Khitan Small Script]. Tōkyō: Research Institute for the Study of Language and Culture of Asia and Africa, Tokyo Foreign Language University.

KANE, Daniel 2009. The Kitan Language and Script. Leiden and Boston: Brill.

KARA, György 1987. 'On the Khitan Writing System.' Mongolian Studies 10: 12-24.

LIU Pujiang 刘浦江 and KANG Peng 康鹏 (eds.) 2014. Qidan xiaozi cihui suoyin 契丹小字词汇 索引 [Index to the Lexicon of Khitan Small Script [inscriptions]. Beijing: Zhonghua Shuju.

RÓNA-TAS, András 2016. 'Khitan Studies I. The Graphs of the Khitan Small Script, 1. General Remarks, Dotted Graphs, Numerals.' AOH 69/2: 117-138.

SHIMUNEK, Andrew 2017. Languages of the Ancient Southern Mongolia and North China. A Historical-Comparative Study of the Serbi or Xianbei Branch of the Serbi-Mongolic Language Family, with an Analysis of Northeastern Frontier Chinese and Old Tibetan Phonology. Wiesbaden: Harrassowitz.

Wu Yingzhe 2012. Kittan shoji shinhakken shiryō shakudoku mondai 契丹小字新発見資料釈読 問題 [Interpretation problems of the newly discovered Khitan Small Script materials]. Tokyo: Research Institute for Languages and Cultures of Asia and Africa, Tokyo Foreign Language University.

Wu Yingzhe and Juha JANHUNEN 2010. New Materials on the Khitan Small Script. Folkstone: Brill.

\section{Sigla of the Major Inscriptions in Khitan Small Script}

\begin{tabular}{|c|l|l|l|l|l|l|}
\hline No. & Sigla & Chinese & ChS $^{1}$ & Date & $\begin{array}{l}\text { Page in } \\
\text { CWJ photo }\end{array}$ & $\begin{array}{l}\text { Initial page } \\
\text { in CWJ }\end{array}$ \\
\hline 1 & Xing & 興 & 兴 & 1055 & 603 & 866 \\
\hline 2 & Ren & 仁 & 仁 & 1076 & 606 & 880 \\
\hline 3 & Lang & 郎 & 郎 & 1134 & 610 & 893 \\
\hline 4 & Dao+gai ${ }^{2}$ & 道+蓋 & 道+盖 & 1101 & 612 & 898 \\
\hline 5 & Xuan+gai & 宣+蓋 & 宣+盖 & 1101 & 621 & 921 \\
\hline 6 & Ling & 令 & 令 & $1057(?)$ & 631 & 935 \\
\hline 7 & Zhong+gai & 仲+蓋 & 仲+盖 & 1150 & 634 & 945 \\
\hline 8 & Xu+gai & 許+蓋 & 许+盖 & 1105 & 642 & 979 \\
\hline 9 & Gu & 故 & 故 & 1115 & 652 & 1012 \\
\hline 10 & Yu & 於 & 于 & 1072 & 658 & 1023 \\
\hline 11 & Hai & 海 & 海 & unknown & 671 & 1093 \\
\hline 12 & Guang & 廣 & 广 & 1053 & 672 & 1099 \\
\hline
\end{tabular}

${ }^{1}$ Chinese Simplified.

2 gai 盖 'canopy'. 


\begin{tabular}{|c|c|c|c|c|c|c|}
\hline No. & Sigla & Chinese & $\mathbf{C h S}^{1}$ & Date & \begin{tabular}{|l} 
Page in \\
CWJ photo
\end{tabular} & $\begin{array}{l}\text { Initial page } \\
\text { in CWJ }\end{array}$ \\
\hline 13 & Zhen & 鎮 & 镇 & 1170 & 679 & 1115 \\
\hline 14 & Hong & 弘 & 弘 & 1100 & 682 & 1139 \\
\hline 15 & Zhuo & 溷 & 溷 & 1108 & 691 & 1159 \\
\hline 16 & Nan & 南 & 南 & 1092 & 692 & 1165 \\
\hline 17 & $\mathrm{Nu}$ & 奴 & 奴 & 1099 & 699 & 1189 \\
\hline 18 & Zhi & 智 & 智 & 1094 & 710 & 1208 \\
\hline 19 & Yong & 永 & 永 & 1088 & 716 & 1224 \\
\hline 20 & Gao & 高 & 高 & unknown & 721 & 1238 \\
\hline 21 & Di & 迪 & 迪 & 1101 & 727 & 1250 \\
\hline 22 & $\mathrm{Tu}$ & 圖 & 图 & 1068 & 735 & 1274 \\
\hline 23 & Tai+gai & 太十蓋 & 太十盖 & 1110 & 741 & 1286 \\
\hline 24 & Song+gai & 宋+盍 & 宋+盖 & 1110 & 749 & 1302 \\
\hline 25 & Qing & 清 & 清 & 1095 & 757 & 1315 \\
\hline 26 & Han & 韓 & 韩 & 1078 & 763 & 1337 \\
\hline 27 & Chao+gai & 抄+蓋 & 抄+盖 & 1082 & 767 & 1350 \\
\hline 28 & GuD & 姑 & 姑 & 1102 & 773 & 1365 \\
\hline 29 & $\mathrm{Sa}+\mathrm{e}^{3}$ & 撒+額 & 撒+额 & 1100 & 779 & 1381 \\
\hline 30 & $\mathrm{Wu}$ & 兀 & 兀 & 1102 & 781 & 1387 \\
\hline 31 & Liang & 梁 & 梁 & 1107 & 792 & 1410 \\
\hline 32 & Xian+gai & 顯+蓋 & 显+盖 & 1175 & 799 & 1430 \\
\hline 33 & DiX & 敵 & 敌 & 1114 & 805 & 1449 \\
\hline 34 & Xiang & 詳 & 详 & 1091 & 815 & 1470 \\
\hline 35 & $\mathrm{Hu}$ & 胡 & 胡 & 1091 & 823 & 1496 \\
\hline 36 & $\mathrm{Pu}+$ gai & 蒲+蓋 & 蒲+盖 & 1105 & 828 & 1517 \\
\hline 37 & Jue & 玦 & 玦 & 1071 & 834 & 1531 \\
\hline 38 & Hui+gai & 回+蓋 & 回+盖 & 1080 & 841 & 1564 \\
\hline 39 & Cha & 査 & 查 & 1113 & 847 & 1577 \\
\hline 40 & Shi & 師 & 师 & 1101 & \multirow{5}{*}{\multicolumn{2}{|c|}{ not included in CWJ }} \\
\hline 41 & ShiZh & 侍 & 侍 & 1091 & & \\
\hline 42 & Wo & 斡 & 斡 & 1099 & & \\
\hline 43 & $\mathrm{Da}$ & 大 & 大 & 1073 & & \\
\hline 44 & Tian & 天 & 天 & 1109 & & \\
\hline
\end{tabular}

${ }^{3} e$ 額 'front piece'. 


\section{Sigla of the Minor Insriptions in the Khitan Small Script}

\begin{tabular}{|l|l|l|l|l|l|l|}
\hline S1 & QingS & 慶 & 庆 & unknown & 853 & 1593 \\
\hline S2 & GuoS & 槨 & 椁 & unknown & $\begin{array}{l}\text { not included } \\
\text { in CWJ }\end{array}$ & 1598 \\
\hline S3 & YuanS & 圓 & 圆 & unknown & 855 & 1599 \\
\hline S4 & BaoS & 寶 & 宝 & unknown & 856 & 1601 \\
\hline S5 & WanS & 完 & 完 & unknown & 857 & 1602 \\
\hline S6 & YuS & 玉 & 玉 & unknown & 858 & 1603 \\
\hline S7 & ShouS & 壽 & 寿 & unknown & 858 & 1604 \\
\hline S8 & Yu yiS & 魚一 & 鱼一 & unknown & 858 & 1604 \\
\hline S9 & Yu erS & 魚二 & 鱼二 & unknown & 858 & 1605 \\
\hline S10 & YanS & 硯 & 砚 & unknown & 860 & 1606 \\
\hline S11 & Ta yiS & 塔一 & 塔一 & unknown & 861 & 1606 \\
\hline S12 & Ta erS & 塔二 & 塔二 & unknown & 862 & 1608 \\
\hline S13 & Ba yiS & 巴一 & 巴一 & unknown & 863 & 1608 \\
\hline S14 & Ba erS & 巴二 & 巴二 & unknown & $\begin{array}{l}\text { not included } \\
\text { in CWJ }\end{array}$ & 1610 \\
\hline S15 & Ba sanS & 巴 三 & 巴三 & unknown & 863 & 1611 \\
\hline S16 & WuS & 烏 & 圆 & unknown & $\begin{array}{l}\text { not included } \\
\text { in CWJ }\end{array}$ & 1612 \\
\hline S17 & YeS & 葉 & 叶 & unknown & 864 & 1612 \\
\hline
\end{tabular}

Ákos Bertalan Apatóczky and András Róna-Tas

Open Access. This is an open-access article distributed under the terms of the Creative Commons Attribution 4.0 International License (https://creativecommons.org/licenses/by/4.0), which permits unrestricted use, distribution, and reproduction in any medium, provided the original author and source are credited, a link to the CC License is provided, and changes - if any - are indicated. (SID_1) 